\title{
RELATO PRÁTICO DE OFICINA DE JORNALISMO IMPRESSO NO ENSINO FUNDAMENTAL DA REDE PÚBLICA MUNICIPAL DE PRESIDENTE PRUDENTE (SP)
}

\author{
Gabriel Batista Mota ${ }^{1}$, Gabriela das Graças Oliveira Leal ${ }^{2}$, Giselle Tomé da Silva ${ }^{3}$ \\ ${ }^{1}$ Especialista em Docência e Gestão na Educação Superior pela Universidade do Oeste Paulista - UNOESTE, Presidente \\ Prudente, SP. E-mail: ogabrielmota@gmail.com \\ ${ }^{2}$ Especialista em Docência e Gestão na Educação Superior pela Universidade do Oeste Paulista - UNOESTE de Presidente \\ Prudente - UNOESTE, Presidente Prudente, SP. \\ ${ }^{3}$ Mestranda em Comunicação pela Universidade Estadual de Londrina - UEL. Docente da Universidade do Oeste Paulista - \\ UNOESTE, Presidente Prudente, SP.
}

\section{RESUMO}

Este artigo, derivado de um projeto de extensão universitário, discute as relações entre a Comunicação e a Educação, por meio de uma oficina prática de jornalismo impresso com alunos da educação fundamental da rede pública municipal de Presidente Prudente (SP). A finalidade foi inserir o jornal na escola objetivando democratizar a linguagem, como também, propagar o hábito da leitura e o contato com outras atividades literárias. Para tanto, apresenta-se o relato da produção de uma edição especial, para o jornal da cidade, confeccionado por estudantes e professores de nove escolas locais.

Palavras-chave: Comunicação e Educação. Jornal na escola. Jornalismo impresso. Ensino fundamental. Presidente Prudente (SP).

\section{PRACTICAL REPORT OF PRINTED JOURNALISM WORKSHOP IN THE FUNDAMENTAL TEACHING OF THE MUNICIPAL PUBLIC NETWORK OF PRESIDENTE PRUDENTE - SP}

\begin{abstract}
This article, derived from a university extension project, discusses the relationships between communication and education, through a practical printed journalism workshop with students of fundamental education of the municipal public network of Presidente Prudente -SP. The purpose was to insert the newspaper in the school objectifying democratizing the language, as well, as propagating the habit of reading and contact with other literary activities. To do so, presents yourself the production report of a special edition, for the city newspaper, made by students and teachers of nine local schools.

Keywords: Communication and education. Newspaper at school. Printed journalism. Fundamental education. Presidente Prudente - SP.

\section{RELATO PRÁCTICO DE OFICINA DE PERIODISMO IMPRESO EN LA ENSEÑANZA FUNDAMENTAL DE LA RED PÚBLICA MUNICIPAL DE PRESIDENTE PRUDENTE (SP)}

\section{RESUMEN}

Este artículo, derivado de un proyecto de extensión universitaria, discute las relaciones entre la Comunicación y la Educación, a través de un taller práctico de periodismo impreso con alumnos de la educación fundamental de la red pública municipal de Presidente Prudente (SP). La finalidad fue insertar el periódico en la escuela objetivando democratizar el lenguaje, como también, propagar el hábito de la lectura y el contacto con otras actividades literarias. Para ello, se presenta el relato de la producción de una 
edición especial, para el periódico de la ciudad, confeccionado por estudiantes y profesores de nueve escuelas locales.

Palabras Clave: Comunicación y Educación. Diario en la escuela. Periodismo impreso. Enseñanza fundamental. Presidente Prudente (SP).

\section{INTRODUÇÃO}

A Comunicação Social, mesmo ainda pouco estudada como ferramenta pedagógica, pode oferecer contribuição prática à Educação ao permitir o uso de ferramentas pouco convencionais ao método de ensino tradicional ${ }^{1}$, como a linguagem do jornalismo impresso, por exemplo, que se destaca por disponibilizar uma possibilidade aos estudantes de introduzirem-se no assunto sugerido com mais destreza já que o nosso país, segundo Pfromm Netto (2011), como a maioria das culturas ocidentais, possui uma conexão mais substancial com o universo da imagem, impressa ou digital.

\begin{abstract}
Assim, longe de pensarmos a aprendizagem como um processo que pode ser bem conduzido por um eficiente método de ensino, ela é um processo que se comunica com linhas de fuga que rompem como os resultados padronizados dos métodos de ensino. (DINIS, 2005, p.77)
\end{abstract}

Pires (2008) afirma que o uso da mídia e imprensa no método de ensino minimiza a oposição que as instituições mais tradicionais fazem frente às diferentes formas de comunicação.

A incorporação da linguagem impressa na Educação é importante tendo em vista que muitos adolescentes e jovens dedicam boa parte de suas horas, e consequentemente sua memória imagética e afetiva, aos recursos midiáticos, como imagens, por exemplo, o que possibilitaria ainda mais sua familiaridade com esta vertente do jornalismo (MORAES, 2005).

Sendo um elemento
enfatizado nas pedagogias
da aprendizagem, a
memória sempre foi vista

\footnotetext{
${ }^{1}$ Entende-se o "ensino tradicional" como aquele centrado na figura do professor, na exposição dogmática e oposto ao ensino moderno que tem $O$ anseio "[...] de incorporar meios e tecnologias de informação" (GÓMEZ, 2002, p.64)
}

tradicionalmente como o elemento que permite armazenar os conteúdos de uma aprendizagem (DINIS, 2005, p.77)

É indispensável salientar que a área jornalística, acima mencionada, viabiliza a criação de material como suplementos, revistas e edições especiais, propiciando a participação dos discentes desde a escolha do tema até o término do produto final.

A universalização do
conhecimento tanto por
meio dos livros quanto pela
didática correta torna-se
fundamental, uma vez que
os alunos teriam que
assimilar conhecimentos -
que seriam posteriormente
exigidos nas relações de
trabalho - e também
internalizar
comportamentos afeitos a
estas relações, tais como
disciplina e pontualidade.
(ZUIN, 2006, p. 48)

O presente artigo apresenta os resultados de um projeto de extensão realizado com nove escolas no ano de 2016 em parceria com o jornal municipal O Imparcial que produz, desde 2010, o programa socioeducativo "O imparcial na escola" que originou a oficina, em questão, aqui relatada.

Assim, considera-se relevante debater as conexões entre estas duas áreas do conhecimento, a fim de promover discussão, interação e cooperação entre elas.

\section{METODOLOGIA}

A presente pesquisa evidencia a iniciativa de estudar e aplicar o uso da linguagem impressa no ensino fundamental da rede pública municipal de ensino de Presidente Prudente (SP). Deste modo, os pesquisadores utilizaram a pesquisa científica como meio para a realização do projeto.

De acordo com Diehl e Tatim (2004, p. 47) a pesquisa científica é um "[...] procedimento 
racional e sistemático, cujo objetivo é proporcionar respostas aos problemas propostos", o que orienta os pesquisadores na busca por opções ao uso educacional do jornalismo impresso, uma vez que auxilia o docente na disseminação de conteúdos diferentes aos discentes.

Em relação ao artigo científico, Lakatos e Marconi (2010, p. 242) explicitam como pequenos estudos, "[...] porém completos, que tratam de uma questão verdadeiramente científica [...]". Ainda conforme as autoras, este tipo de trabalho possibilita ao leitor reforçar a experiência da leitura do exercício proposto no texto.

Para a realização deste artigo, foi usada a pesquisa tipo intervenção, pois havia necessidade de interferir nas atividades habituais da escola e das turmas. Segundo Rocha e Aguiar (2003, p. 67), a pesquisa-intervenção aprofunda a ruptura com os enfoques tradicionais e expande as bases teóricos-metodológicas das pesquisas participativas.

Castro e Besset (2008, p. 11) acrescentam que:

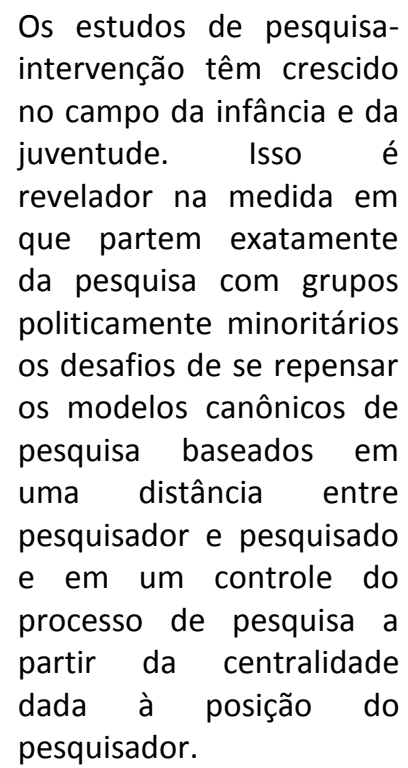

A fim de colocar em prática o projeto, usou-se como método a pesquisa bibliográfica para auxiliar na escolha de materiais eletrônicos e impressos pertinentes ao tema, que ajudaram a compor o presente artigo. Lakatos e Marconi (2010, p. 166) enfatizam que esta forma de coleta de dados ressalta a necessidade do contato direto ao conteúdo já produzido relacionado ao assunto.

Com o objetivo de angariar dados, a técnica de observação direta intensiva foi usada.
Lakatos e Marconi (2010, p. 173) explicam que essa técnica não "[...] consiste apenas em ver e ouvir, mas também em examinar fatos ou fenômenos que se deseja estudar", como também pode-se conseguir informações por meio dos sentidos de aspectos da realidade. Os pesquisadores usaram a técnica acima para observar a interação da turma com a professora.

Por fim, o projeto de extensão possui papel importante em relação às contribuições que pode trazer frente à sociedade, conforme Rodrigues et al. (2013, p. 142), "[...] colocar em prática aquilo que foi aprendido em sala de aula e desenvolvê-lo fora dela. A partir do momento em que há esse contato entre o aprendiz e a sociedade beneficiada por ele, acontece por parte dos dois lados, benefícios".

\section{JORNALISMO IMPRESSO COMO FERRAMENTA PEDAGÓGICA}

O jornalismo nasceu impresso. Conforme Barth, Serpa e Pimenta (2015) mesmo com o passar das décadas e com a evolução da escrita, o jornalismo impresso alcançou o auge e popularidade no século XX. "Pesquisas da época chegaram a registrar que um em cada dois norteamericanos adultos lia jornais. Assim referenciamos a então era moderna, chamada 'da Informação'" (BARTH; SERPA; PIMENTA, 2015, p. 1).

No Brasil, assim como nos demais países da América Latina, a imprensa periódica, segundo Lutz (2013), tem uma história mais recente se comparada aos países europeus, com o início da produção de impressos a partir do século XIX. Na educação, esta vertente do jornalismo está entre os meios de comunicação mais utilizados e há mais tempo (LUTZ, 2013). "As primeiras publicações modernas do gênero datam do século XVII, antes, portanto, das demais mídias" (LUTZ, 2013, p. 2).

Ainda conforme o autor:

Duas das características que contribuíram para o uso do jornal como ferramenta pedagógica ao longo do tempo são as facilidades para acesso e produção - os impressos não necessitam de aparelhos eletrônicos para reprodução nem equipamentos para produção e edição, como câmeras, caixas de som, 
microfones ou computadores. Um jornal escolar pode, inclusive, ser feito a mão e mimeografado ou fotocopiado (LUTZ, 2013, p. 2).

Em sala de aula, o jornal, ainda é uma proposta metodológica que possui um recurso de grande adesão e interesse por parte dos discentes, pois apesar de existirem outras mídias consideradas, superficialmente, mais atrativas, "[...] o fato do registro físico do jornal impresso apesar das versões digitais - ser algo formalizado, que pode ser levado e mostrado aos demais sujeitos, o jornal tem boa circulação entre os grupos sociais e escolares" (PUNTEL; HOEZEL, 2013, p.5).

Nesse contexto, o jornal pode estar inteiramente ligado ao reforço e o treino da leitura, porém não se limita a essa prática. Ainda conforme Puntel e Hoezel (2013, p. 5) o veículo torna-se uma atraente ferramenta educacional para o docente demonstrar que por meio "[...] desse recurso, ele pode se expressar, evidenciando sua forma de ver, sentir e questionar tudo que lhe agrada ou incomoda, e que isso tem importância e que ele é importante".

Como sugere Assumpção (2009), o impresso, como recurso de mídia e meio de comunicação, tende a sugerir que os estudantes de classe de alfabetização necessitam de uma análise apurada do professor, utilizando nas ações pedagógicas diversos jornais produzidos por distintas empresas jornalísticas.

Albuquerque e Fonseca (2012) acrescentam que se deve, também, levar em consideração o contexto social dos indivíduos, uma vez que a educação se apresenta com a função de criar cidadãos críticos, onde o discente não apenas decifra a mensagem, como também questiona e defende seus pontos de vista.

Os benefícios proporcionados pelo uso dos jornais no ambiente escolar atuam como fonte primária de informação. Para Faria (2006), os impressos são mediadores entre a escola e a sociedade, pois colocam os discentes em contato com múltiplos assuntos e, além disso, auxilia na construção de novas formas de olhar, o que reflete na vida social dos estudantes.

É importante também deixar para os estudantes os diversos sistemas e suportes de texto jornalístico que, para Lutz (2013, p. 4), explicam "[...] o processo de construção da notícia, bem como questionar o mito da objetividade jornalística, através da distinção entre fato e versão".

As vantagens da criação de impressos escolares são avaliadas há décadas. Faria e Zanchetta Jr. (2007) destacam que a produção dos informativos em sala de aula deve estar voltada à interdisciplinaridade, pois envolve os docentes, discentes, pais, funcionários da instituição e a comunidade.

Lutz (2013, p. 5) acrescenta que:

o jornal deve ser produzido levando-se em consideração a definição de itens como conteúdo, periodicidade, nome/logotipo, impressão, recursos, distribuição. A publicação também deve evitar se tornar um mero repetidor dos conteúdos dos livros didáticos, pois o públicoalvo pode perder o interesse. É importante ainda não fechá-la a um número restrito de pessoas, fazendo com que as informações não circulem da maneira devida, além de evitar com que o jornal se resuma unicamente a textos pessoais dos alunos, bem como piadas, poesias, etc.

No que diz respeito ao futuro destes jornais, o impresso ainda encontra espaço na educação, especialmente na produção de informativos escolares, representando uma opção divertida, que pode propor interação e interdisciplinaridade entre os alunos, além de baixo custo à escola.

Mesmo assim, os
impressos tendem a ser
mais acessíveis à
comunidade, uma vez que
estão à disposição para a
leitura o tempo todo e não
necessitam de outros
meios para a circulação -
um blog requer, por
exemplo, que o usuário
tenha um computador
conectado à internet para 
acessar as informações (LUTZ, 2013, p. 8).

Entretanto, de um modo geral, os autores do presente artigo observam que a integração deve ser realizada sem abandonar totalmente, ou repentinamente, as mídias mais populares - como TV, rádio, jornal impresso ou revista - pois, como são mais conhecidas e de fácil acesso manual, ou seja, sem necessidade de acesso à internet, tornam-se o caminho mais favorável no contexto escolar, tendo em vista que nem toda escola possui equipamentos ou conexão com a Web.

\section{PROGRAMA "O IMPARCIAL NA ESCOLA"}

O programa socioeducativo "O Imparcial na Escola" é uma idealização do jornal O Imparcial, de Presidente Prudente (SP), para fomento da cidadania. A ação se consolida com o fornecimento de exemplares às escolas ou Secretarias de Educação conveniadas para utilização em sala de aula. Ao mesmo tempo, capacitações são promovidas com os educadores com visitas para habilitá-los ao uso do veículo de comunicação como instrumento de aprendizagem.

O programa tem como objetivo central oportunizar o acesso ao meio jornal como uma das dimensões do estímulo ao prazer de ler, bem como reinterpretar a vertente e seus vínculos com a realidade social, criar alternativas para expressão de atitudes cidadãs por parte dos leitores, diante das informações por eles veiculadas.

Desde 2010, o impresso mantém parceria com a Secretaria Municipal de Educação de Presidente Prudente, com o fornecimento de 10 exemplares para cada uma das 31 escolas da rede pública municipal, que atendem cerca de 10 mil alunos.

Em 2011, iniciaram-se as formações para todos os 400 professores e gestores do ensino fundamental. Nos encontros, os profissionais conheceram e exercitaram, em oficinas práticas, atividades interdisciplinares para execução em sala de aula. Não há fórmula pronta para a execução, mas sim um estímulo, com orientação e exemplos, para que a criatividade seja exacerbada e, então, colocada em prática. A ação não visa, em momento algum, competir com os livros didáticos, nem mesmo substituir a grade elaborada pela rede. Pretende-se, no entanto, somar, levar conhecimento, factualidade, fomentar a cidadania, a democracia, bem como direitos e deveres. Desta forma, este trabalho representa o primeiro contato que alguns alunos têm com o impresso.

Ao longo dos anos, toda produção com o jornal na escola ganhou visibilidade com matérias jornalísticas e suplementos especiais. Além disso, uma coluna publicada semanalmente retrata o que os alunos e educadores promovem dentro e fora da sala de aula com o emprego do impresso, objetivando propagar a metodologia criada pelos educadores aos demais colegas.

Em outro formato, anteriormente denominado "Jornal na Escola", o trabalho já foi desenvolvido na região prudentina, em parceria com a Diretoria Regional de Ensino (Derpp), alcançando a capacitação de 1,3 mil educadores.

\section{A OFICINA}

A edição de 2016 do programa "O Imparcial na escola" teve início no segundo semestre do ano mencionado com as escolas que manifestaram interesse. As nove instituições participantes foram: E.M. Pioneiro Alberto Bernardes Sotelo (Floresta do Sul), E.M. Carlos Alberto Arruda Campos (Eneida), E.M. Dr. Carlos Braga (Ameliópolis), E.M. Prof. Ivo Garrido (Jardim Mediterrâneo), E.M. Profa. Maria do Socorro Brito de Almeida (Cecap), E.M. Prof. Oacyr Azevedo (Jardim Eldorado), E.M. João Sebastião Lisboa (Vila Charlotte), E.M. Rui Carlos Vieira Berbert (Brasil Novo) e E.M. Profa. Vilma Alvarez Gonçalvez (Jardim Paraíso).

A primeira etapa teve início com a realização de nove reuniões entre o editor executivo do jornal O Imparcial, e coordenador do programa, e os professores e gestores dos ambientes educacionais listados anteriormente. Estes encontros objetivaram a introdução ao programa, como também a capacitação sobre o modo de produção tanto de um jornal impresso como de um suplemento, seção do jornal na qual o produto final seria hospedado impresso e virtualmente.

Diante disto, a fase seguinte do projeto de extensão foi a seleção de estudantes de jornalismo da Universidade do Oeste Paulista (Unoeste) que iriam compor o quadro de assistentes. Os universitários que se voluntariaram, sob a supervisão da docente responsável pela disciplina de Jornalismo Impresso, foram divididos em três equipes, onde cada uma se responsabilizou em orientar três escolas da cidade na produção de seu material. Cada unidade escolar disponibilizou turmas e 
professores para o programa, ficando a cargo destes a escolha do tema e de como o mesmo seria trabalhado.

Os assuntos escolhidos pelos participantes foram os seguintes: dengue, vida no distrito, higiene, olimpíadas, folclore, xadrez, respeito e cidadania, o morador mais antigo do bairro, alimentação saudável, diversidade étnicoracial, valores morais e éticos, clima, moradias da Companhia de Desenvolvimento Habitacional e Urbano do Estado de São Paulo (CDHU), animais, sustentabilidade, educação cívica, semana da criança, visita ao jornal O Imparcial, a importância de brincar, curiosidades, obesidade infantil, solidariedade, oficinas Cidadescola, meio ambiente, poluição, animais peçonhentos, bullying, terreno baldio, atualidades, notícias diárias, reciclagem, eleições, política, pipa vs. cerol, sexualidade, Cooperlix e eventos na escola. Estes temas foram trabalhados por meio de textos informativos, literatura de cordel, tirinhas, desenhos, cruzadinhas, entrevistas, galerias de imagens e fotos, charges, caça-palavras, receitas, brincadeiras (os 07 erros, passatempo e ligar os pontos), artigos, paródias, parlendas, carta ao leitor, classificados, fábulas e contos.

A terceira parte do projeto constituiu-se de três visitas que as equipes de universitários faziam, em cada uma das três escolas sob sua responsabilidade, orientando-as sobre diagramação de seu material, métodos de produção e organização jornalísticas e conteudísticas a fim de uniformização do produto final.

Durante toda a realização da oficina, os universitários responsáveis por cada escola relatavam à professora-orientadora do projeto e ao coordenador do programa as opiniões emitidas pelas crianças e pelos(as) educadores(as), observando atentamente a recepção, assim como as dificuldades, enfrentadas por estes públicos.

Foi possível perceber a evolução de cada sala, os questionamentos e a forma como cada uma construía suas tarefas. Com o passar das semanas, os alunos começaram a questionar, sem nenhuma interferência dos pesquisadores ou dos docentes, os assuntos por eles mesmos escolhidos e a sugerir novas abordagens, evidenciando que haviam, enfim, assimilado não apenas o assunto, mas também a forma como a Comunicação, em especial o jornal impresso, tratava os temas presentes no universo pedagógico.
Após um período de aproximadamente três semanas, as turmas finalizaram seus trabalhos e os professores, responsáveis por cada uma delas, se reuniram com o coordenador do programa entre os dias 29 de agosto e 28 de setembro para apresentar o conteúdo construído e receber as últimas orientações. Em seguida, o material seguiu para a sede do jornal onde foi editado e diagramado para a versão final ${ }^{2}$ da edição de 2016.

\section{CONSIDERAÇÕES FINAIS}

O envolvimento entre áreas distintas, como a Comunicação e a Educação, é interessante para podermos perceber que campos do conhecimento diferentes podem se complementar e oferecer acréscimos de grande importância um ao outro, uma vez que temos a ciência de que o saber, em si, é fluido e sem ligação enraizada com um setor em específico, isto é, podemos encontrar o conhecimento em qualquer lugar, ou profissão, ainda mais quando se complementam e cooperam em prol de um objetivo em comum.

A participação de jornalistas no ambiente escolar é um assunto que deve ser encorajado, não apenas pelo motivo de que isto traz benefícios para ambas as partes envolvidas, mas também porque quebra o arquétipo de que professores e jornalistas devem, apenas, atuar em suas áreas de formação e que a colaboração com outros setores não faria sentido à organização jurássica de nossa sociedade ocidental.

Outro ponto importante a ser descrito foi a abertura das escolas e da Secretaria Municipal de Educação para projetos e ações externas que visassem a melhoria do sistema educacional local promovendo trabalhos diferenciados e inovações.

Durante todo o período de realização do programa foi interessante perceber a participação intensa de todos os alunos das turmas que as escolas disponibilizaram. Trabalhar algo novo e diferente não era apenas cativante, mas também desafiador. Em diversos momentos o questionamento sobre a razão em trabalhar aquele determinado assunto naquele formato

\footnotetext{
2 O produto final da oficina, em formato PDF e gratuito, pode ser acessado virtualmente em: https://drive.google.com/file/d/1qk4eqaSIOP24k3W35juU3XI3uuHy mHFM/view ou https://ogabrielmota.files.wordpress.com/2016/11/pec3a7a-finalprojeto-o-imparcial-na-escola-20163.pdf
} 
específico levava tanto os professores quanto os estudantes ao pensamento e argumentação para defenderem suas ideias e também perguntarem como aquele tema seria melhor configurado, ou diagramado, para o formato jornalístico impresso.

Ao observarmos mais atentamente todo o percurso de produção do suplemento de 2016 do "O Imparcial na escola" é possível perceber, segundo relato dos professores, uma série de pontos positivos no cotidiano destas turmas, como por exemplo, dedicaram-se mais à leitura, envolvimento em sala de aula, assim como com a escola e a sociedade, além do incentivo à cidadania, ao olhar crítico para o meio ao seu redor e a divulgação e estimulação de novas turmas aos projetos futuros.

Em relação aos estudantes de jornalismo que orientaram as instituições, também houve benefícios como o olhar social, o desejo para futuras ações de extensão que leve o conhecimento adquirido para fora dos muros da universidade, como também a produção prática do que aprendem em sala de aula em prol da cidadania, da escola e comunidade.

Por fim, os autores deste artigo concluem que atividades que compactuam com a relação Comunicação-Educação são sempre muito bemvindas ao cenário escolar, pois podem não apenas oferecer estímulos e conteúdos diferenciados para ela, mas também novas ferramentas pedagógicas que podem auxiliar aos docentes em suas tarefas diárias e na transmissão do conhecimento cada vez mais complexo, midiático, visual e digital do século XXI.

\section{REFERÊNCIAS}

ALBUQUeRQUE, Moisés Henrique Cavalcanti de; FONSECA, Ailton Siqueira de Sousa. A construção do conhecimento a partir da leitura do jornal impresso em sala de aula. In: COLÓQUIO INTERNACIONAL "EDUCAÇÃO E CONTEMPORANEIDADE", 7., 2012, São Cristóvão. Anais eletrônicos [...] São Cristóvão: FACED, 2012. Disponível em: http://www.gpecpop.faced.ufu.br/node/90. Acesso em: 22 out. 2018.

ASSUMPÇÃO, Zeneida Alves de. Mídias-educação e o jornal na sala de aula - um estudo comparativo dos projetos vamos ler em dois jornais paranaenses: Jornal da Manhã e Tribuna do Norte. Revista Analecta, Paraná, v. 10, n. 2, p. 67-82, jul./dez., 2009. https://revistas.unicentro.br/index.php/analecta/arti cle/viewFile/2099/1802. Acesso em: 22 out. 2018.

BARTH, Daiani; SERPA, Leoní; PIMENTA, Thales Henrique. $O$ jornalismo impresso enquanto instrumento pedagógico: a publicação da revista In Loco em Vilhena RO. In: CONGRESSO BRASILEIRO DE CIÊNCIAS DA COMUNICAÇÃO, 38., 2015, Rio de Janeiro. Anais eletrônicos [...] Rio de Janeiro: Sociedade Brasileira de Estudos Interdisciplinares da Comunicação, 2015. Disponível em: http://portalintercom.org.br/anais/nacional2015/res umos/R10-2631-1.pdf. Acesso em: 23 out. 2018.

CASTRO, Lucia Rabelo de; BESSET, Vera Lopes. Pesquisa-intervenção na infância e juventude: construindo caminhos. Rio de Janeiro: Nau, 2008. Disponível em:

http://www.nipiac.ufri.br/producao2/item/690pesquisa-interven\%C3\%A7\%C3\%A3o-nainf\%C3\%A2ncia-e-juventude-construindo-caminhos. Acesso em: 30 abr. 2019.

DIEHL, Astor Antônio; TATIM, Denise Carvalho. Pesquisa em ciências sociais aplicadas: métodos e técnicas. São Paulo: Prentice Hall, 2004.

DINIS, Nilson Fernandes. Educação, cinema e alteridade. Educar, Curitiba, n. 26, p. 1-13, fev./abr., $2005 . \quad$ Disponível em: http://www.scielo.br/pdf/er/n26/n26a06.pdf. Acesso em: 30 abri. 2019.

FARIA, Maria Alice. Como usar o jornal na sala de aula. São Paulo: Contexto, 2006.

FARIA, Maria Alice; ZANCHETTA JR., Juvenal. Para ler e fazer o jornal na sala de aula. São Paulo: Contexto, 2007.

GÓMEZ, Guillermo Orozco. Comunicação, educação e novas tecnologias: tríade do século XXI. Comunicação \& Educação, São Paulo, v. 8, n. 23, p. 57-70, jan./abr., 2002. Disponível em: http://www.revistas.usp.br/comueduc/article/view/ 37017. Acesso em: 28 abri. 2019.

LAKATOS, Eva Maria; MARCONI, Marina de Andrade. Fundamentos de metodologia científica. 7. ed. São Paulo: Atlas, 2010.

LUTZ, Cleyton Pereira. O jornal impresso na educação: usos e perspectivas. In: JORNADA DA HISTEDBR, 6., 2013, Cascavel. Anais eletrônicos [...] 
Cascavel: UNICAMP, 2013. Disponível em: http://www.histedbr.fe.unicamp.br/acer histedbr/jo rnada/jornada11/artigos/9/artigo simposio 9823 cleyton.lutz@ifms.edu.br.pdf. Acesso em: 22 out. 2018.

MORAES, Carlos Vinicius Oliveira de. De um mundo da escola para uma escola do mundo: reflexão sobre meios e sobre fins. Comunicação \& Educação, São Paulo, v. 10, n. 3, p. 297-304, set./dez., 2005. Disponível em: https://doi.org/10.11606/issn.23169125.v10i3p297-304. Acesso em: 19 out. 2018.

PFROMM NETTO, Samuel. A Odisseia do Cinema Educativo no Brasil. In: PFROMM NETTO, Samuel. Telas que ensinam, Mídia e aprendizagem: do cinema às tecnologias digitais. 3. ed. Campinas: Alínea, 2011. p. 101-124.

PIRES, Eloíza Gurgel. A experiência audiovisual nos espaços educativos. Comunicação \& Educação, São Paulo, v. 13, n. 2, p. 281-295, mai./ago., 2008. Disponível em: http://www.revistas.usp.br/comueduc/article/view/ 42298/45969. Acesso em: 19 out. 2018.

PUNTEL, Michele; HOEZEL, Carlos Gustavo Martins. 0 uso do jornal impresso em sala de aula: abordagens no contexto da alfabetização/letramento. 2013. 15 f. Monografia (Especialização), Faculdade de Mídias na Educação, Universidade Federal de Santa Maria, Santa Maria, 2013.

ROCHA, Marisa Lopes da; AGUIAR, Katia Faria de. Pesquisa-intervenção e aprodução de novas análises. Psicologia: ciência e profissão, Brasília, v. 23 , n. 4, p. 64-73, dez., 2003. Disponível em: http://pepsic.bvsalud.org/pdf/pcp/v23n4/v23n4a 10.pdf. Acesso em: 30 abr. 2019.

RODRIGUES, Andréia Lilian Lima; PRATA, Michelle Santana; BATALHA, Taíla Beatriz Silva; COSTA, Carmen Lúcia Neves do Amaral; PASSOS NETO, Irazano de Figueiredo. Contribuições da extensão universitária na sociedade. Cadernos de Graduação: Ciências Humanas e Sociais, Aracaju, v. 1, n. 16, p. 141-148, mar., 2013. Disponível em: https://periodicos.set.edu.br/index.php/caderno humanas/article/viewFile/494/254. Acesso em: 30 abr. 2019.

ZUIN, Antônio. Educação e Comunicação: uma abordagem histórico-filosófica. Educação \&
Realidade, Porto Alegre, v. 31, n. 2, p. 43-60, jul./dez., 2006. Disponível em: http://seer.ufrgs.br/index.php/educacaoerealida de/article/view/6844/4115. Acesso em: 30 abri. 2019. 